\title{
1 Additive genetic variance for lifetime fitness and the capacity for adaptation in an
}

\section{2 annual plant}

4 Mason W. Kulbaba ${ }^{1, £}$, Seema N. Sheth ${ }^{1,2}$, Rachel E. Pain ${ }^{1}$, Vince M. Eckhart ${ }^{3}$, Ruth G. Shaw ${ }^{1}$

$6 \quad £$ corresponding author: mason.kulbaba@gmail.com

$7 \quad{ }^{1}$ Department of Ecology, Evolution, and Behavior, University of Minnesota, St. Paul, MN, USA.

$8{ }^{2}$ Department of Plant and Microbial Biology, North Carolina State University, Raleigh, NC,

9 USA. ${ }^{3}$ Department of Biology, Grinnell College, Grinnell, IA, USA

22 Running head: Capacity for adaptation in an annual plant

24 Key words: Chamaecrista fasciculata, adaptive capacity, aster models, genotype-by-

25 environment interactions, Fisher's Fundamental Theorem of Natural Selection 


\section{Abstract}

27 The immediate capacity for adaptation under current environmental conditions is directly

28 proportional to the additive genetic variance for fitness, $V_{A}(W)$. Mean absolute fitness, $\bar{W}$, is

29 predicted to change at the rate $\frac{\mathrm{V}_{\mathrm{A}}(\mathrm{W})}{\overline{\mathrm{W}}}$, according to Fisher's Fundamental Theorem of Natural

30 Selection. Despite ample research evaluating degree of local adaptation, direct assessment of

$31 \quad \mathrm{~V}_{\mathrm{A}}(\mathrm{W})$ and the capacity for ongoing adaptation is exceedingly rare. We estimated $\mathrm{V}_{\mathrm{A}}(\mathrm{W})$ and

$32 \overline{\mathrm{W}}$ in three pedigreed populations of annual Chamaecrista fasciculata, over three years in the

33 wild. Contrasting with common expectations, we found significant $\mathrm{V}_{\mathrm{A}}(\mathrm{W})$ in all populations and

34 years, predicting increased mean fitness in subsequent generations ( 0.83 to 6.12 seeds per

35 individual). Further, we detected two cases predicting "evolutionary rescue", where selection on

36 standing $\mathrm{V}_{\mathrm{A}}(\mathrm{W})$ was expected to increase fitness of declining populations $(\overline{\mathrm{W}}<1.0)$ to levels

37 consistent with population sustainability and growth. Within populations, interannual differences

38 in genetic expression of fitness were striking. Significant genotype-by-year interactions reflected

39 modest correlations between breeding values across years (all $r<0.490$ ), indicating temporally

40 variable selection at the genotypic level; that could contribute to maintaining $\mathrm{V}_{\mathrm{A}}(\mathrm{W})$. By directly

41 estimating $\mathrm{V}_{\mathrm{A}}(\mathrm{W})$ and total lifetime $\overline{\mathrm{W}}$, our study presents an experimental approach for studies

42 of adaptive capacity in the wild. 


\section{Introduction}

A population's mean absolute fitness, $\overline{\mathrm{W}}$, in terms of the per capita contribution of

45 offspring, corresponds to its growth rate and is thus a measure of its degree of adaptation (Fisher

46 1930, pp. 25, 37; Roughgarden 1996, Ch. 4). Fisher (1930) showed that the immediate capacity

47 for further adaptation is proportional to the magnitude of a population's additive genetic variance

48 for absolute fitness, evaluated as an individuals' lifetime contribution of offspring to the

49 population (Fisher 1930; Price 1970, 1972; Ewens 2004). Moreover, this Fundamental Theorem

50 of Natural Selection (FTNS, Fisher 1930) quantitatively predicts the rate of adaptation under

51 prevailing environmental conditions as the ratio of $\mathrm{V}_{\mathrm{A}}(\mathrm{W})$ to current mean population fitness, $\overline{\mathrm{W}}$.

52 This ratio predicts the genetically based change, from one generation to the next, in the per capita

53 rate of population growth. Such predictions are vital to understanding the adaptive process, by

54 first determining the possibility for evolutionary change in mean fitness, and second, the

55 expected magnitude of fitness increase in the wild. Thus, using FTNS to predict future adaptation

56 under ongoing natural selection requires direct, quantitative estimates of standing additive

57 genetic variance for fitness, $\mathrm{V}_{\mathrm{A}}(\mathrm{W})$. Studies that take such a direct and predictive approach are

58 exceedingly rare (but see Etterson 2004a,b; Winn 2004; Sheth et al. 2018).

Studies of ongoing selection have generally focused on traits of particular interest. Lande

60 and Arnold's (1983) proposal of multiple regression of fitness on traits powerfully stimulated

61 research of this kind. As they noted, this approach reflects only the selection on those traits under

62 consideration, through their associations with the measure of fitness. Few such studies report the

63 extent to which the included traits account for the variation in fitness (but see Conner 1988;

64 Janzen 1993; Conner et al. 1996a,b). Natural selection likely bears on many more traits,

65 however, and this implies that the included traits typically account for a modest proportion of the 
variation in fitness (see Shaw 2019). Whereas the regression of fitness on a set of traits can yield

67 insight into evolutionary change in particular traits under selection, they are ill-suited for

68 predicting the change in mean absolute fitness, i.e. the degree of overall adaptation.

Retrospective studies of genetic differentiation and adaptation to changes in local conditions have amply demonstrated the efficacy of selection in the past. These cases are

71 illuminating even when the aspect(s) of the environment that impose(d) differential selection are

72 unknown, as is often the case, given the high dimensionality of environment. When the timing of

73 an abrupt environmental change is known, the rate that adaptation proceeded can also be

74 determined, or at least bounded. Cases of rapid adaptation, within a few to tens of generations,

75 are now well known for a variety of taxa and include adaptation that followed changes in edaphic

76 conditions (Antonovics and Bradshaw 1970; Al-Hiyaly et al. 1993), introduction of herbicides

77 (Vigueira et al. 2013; Baucom 2019), predators (Fisk et al. 2007), and changing climate (Franks

78 et al. 2007; Geerts et al. 2015). These examples of rapid adaptation to local conditions reveal

79 capacity for adaptation to environmental differences from standing genetic variation (Barrett and

80 Schluter 2008). However, such studies are limited to characterizing the current degree of

81 adaptation in response to past selection and do not evaluate the potential for ongoing adaptation.

83 ongoing adaptation in wild populations, especially in assessing whether standing levels of

$84 \mathrm{~V}_{\mathrm{A}}(\mathrm{W})$ suffice for contemporary natural selection in declining populations (i.e. $\left.\overline{\mathrm{W}}<1\right)$ to halt

85 further decline (Bradshaw 1991). Such "evolutionary rescue" (Gomulkiewicz and Holt 1995)

86 that increases fitness to 1 (i.e. individuals demographically replacing themselves) or greater

87 depends on current standing $\mathrm{V}_{\mathrm{A}}(\mathrm{W})$. However, a sufficient $\mathrm{V}_{\mathrm{A}}(\mathrm{W})$ for such fitness increase is

88 unknown, particularly in wild populations subject to substantial spatial and temporal 
environmental variation (Carlson et al. 2014). In the current context of drastic ongoing

90 environmental change, estimates of the magnitude of a populations' $\mathrm{V}_{\mathrm{A}}(\mathrm{W})$ are critical for

91 predicting the genetically-based change in $\overline{\mathrm{W}}$ in response to the natural selection impinging on

92 them. Given the elevated threat to population persistence due to rapid change in climate and

93 other aspects of the environment (Shaw and Etterson 2012; Neumann et al. 2017), it is now

94 imperative to clarify the efficacy of selection in maintaining and enhancing population mean

95 fitness in situ.

Despite their importance, very few direct estimates of standing $\mathrm{V}_{\mathrm{A}}(\mathrm{W})$ exist (but see

97 Etterson 2004a,b; Winn 2004; Sheth et al. 2018). Several factors may explain this paucity of

98 empirical research. First, population mean fitness is often thought to be at or near optimum due

99 to incessant selection, which would tend to fix or eliminate alleles having directional effects on

100 fitness. Accordingly, $\mathrm{V}_{\mathrm{A}}(\mathrm{W})$, and therefore the capacity for adaptation, is conjectured to be

101 reduced to low or negligible levels (e.g., Mazer 1987; Barton and Keightley 2002). However,

102 even with consistent and strong selection at individual loci, fixation requires hundreds of

103 generations (e.g., Fig. 6.3 in Hartl and Clark 1997; Messer et al. 2016). The continuing response

104 to selection in the Illinois corn selection experiment (Moose et al. 2004), even after 100

105 generations, demonstrates the persistence of variation supporting a response to artificial selection

106 on biochemical constituents of kernels. However, the resilience of variation under selection in

107 nature remains an open empirical question. Second, numerous studies have found that estimates

108 of narrow-sense heritability $\left(\frac{V_{A}}{V_{P}}\right)$ for individual fitness components tend to be lower than for

109 morphological traits (Roff and Mousseau 1987; McFarlane et al. 2014). Because environmental

110 variation inherent to fitness components is compounded with environmental variance of

111 underlying morphological traits, high environmental variance, rather than low additive genetic 
112 variance, may explain low heritability of fitness components (Price and Schluter 1991).

113 Nevertheless, the empirical generalization about lower heritability of individual components of

114 fitness contributed to the expectation that additive genetic variance for lifetime fitness is likely to

115 be modest. This expectation may, however, be inaccurate because it does not account for the

116 dependence of sequential fitness components through the life-span. Third, when pedigrees are

117 not experimentally derived and may be uncertain (e.g. Foerster et al. 2007), logistical challenges

118 encumber efforts to both reconstruct relatedness of individuals and determine total lifetime

119 fitness. Uncertainty in the assignment of relatedness casts doubt on the estimates of quantitative

120 genetic parameters (Thomas et al. 2000). Finally, confounding between genetic and

121 environmental influences, likely in observational studies, can also bias $\mathrm{V}_{\mathrm{A}}(\mathrm{W})$ estimates

122 (Pemberton 2010), and therefore inferences drawn from them.

124 substantial genetic variation could be maintained is ambiguous. In particular, early theory

125 addressing the role of environmental variation, particularly temporal variability, indicated that

126 restrictive conditions are required to maintain genetic variation within populations (Felsenstein

127 1976; Hedrick 1986; Gillespie and Turelli 1989). More recently, models focusing on $\mathrm{V}_{\mathrm{A}}(\mathrm{W})$

128 under environmentally varying selection have demonstrated maintenance of substantial $\mathrm{V}_{\mathrm{A}}(\mathrm{W})$

129 (Zhang 2012; Shaw and Shaw 2014; see also Yi and Dean 2013).

130 Direct estimation of $\mathrm{V}_{\mathrm{A}}(\mathrm{W})$ is not a trivial endeavor, requiring sound experimental design

131 and statistical inference. Experimental approaches that facilitate estimates of complete lifetime

132 fitness expressions from fully pedigreed individuals, and avoid confounding environmental and

133 genetic effects are essential (Shaw 2019). Further, statistical tools are needed that can validly

134 model lifetime fitness, which conforms to no conventional statistical distribution (Shaw et al. 
135 2008). Aster models account for the dependent nature of sequential life-history fitness

136 expressions to estimate total mean lifetime fitness (Geyer et al. 2007), and random parental

137 effects (Geyer et al. 2013) to estimate the additive genetic effects on lifetime fitness.

138 In this study, we estimate the capacity for adaptation under contemporary natural

139 selection in wild populations of the annual legume Chamaecrista fasciculata growing in their

140 native locations. Using Fisher's Fundamental Theorem (Fisher 1930) and aster modelling to

141 analyze records of lifetime fitness (Geyer et al. 2007, 2013), we directly estimate $\mathrm{V}_{\mathrm{A}}(\mathrm{W})$ and

$142 \bar{W}$ to quantitatively predict the rate of adaptation. To assess the generality of our findings, we

143 conducted our experiment in three populations in three successive years. Our experimental

144 design allowed us to characterize population-specific expression of $\mathrm{V}_{\mathrm{A}}(\mathrm{W})$ and to predict the rate

145 of future adaptation, while also evaluating temporal variation in the expression of $\mathrm{V}_{\mathrm{A}}(\mathrm{W})$, and

146 therefore variation in the capacity for adaptation, in three populations over three years.

\section{Materials and Methods}

148 Study system

149 We estimated $\mathrm{V}_{\mathrm{A}}(\mathrm{W})$ and $\overline{\mathrm{W}}$ as the basis for predicting the generational change in mean

150 fitness in three populations (Fig. 1) of the annual legume Chamaecrista fasciculata, each

151 growing in its home site. The range of $C$. fasciculata spans from the prairies of the Northern

152 Great Plains in Minnesota to Central Mexico and to the eastern seaboard of North America

153 (Irwin and Barneby 1982). C. fasciculata produces hermaphroditic, enantiostylous flowers that

154 are buzz-pollinated (Lee and Bazzaz 1982) by bumblebees (Bombus spp). Its experimental

155 tractability has made it the focus of previous studies of gene flow (Fenster 1991a,b), quantitative

156 genetics (Kelly 1993; Etterson 2004b), selection on traits (Etterson 2004a), local adaptation 
157 (Galloway and Fenster 2000), adaptation to climate change (Etterson and Shaw 2001; Etterson

158 2004b), evolution of range limits (Stanton-Geddes et al. 2012b, 2013), and genotype-by-

159 environment interactions (Sheth et al. 2018).

160 Genetic sources and pedigree design

In the fall of 2012, 2-3 fruits from 200 maternal plants no closer together than $10 \mathrm{~m}$ were

162 collected from a population of $C$. fasciculata occupying remnant prairie at Kellogg-Weaver

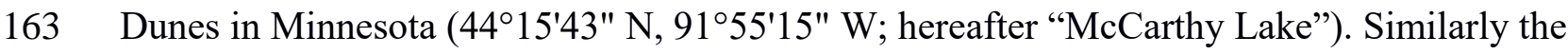

164 following fall, fruits from 200 maternal plants were collected from populations of C. fasciculata

165 at Grey Cloud Dunes Scientific and Natural Area in Minnesota (4446'32"N, 9301'38"W;

166 hereafter "Grey Cloud"), and 100 fruits from plants at the Conard Environmental Research Area

167 in Iowa (4140'44.2"N 92०51'24.9"W; hereafter “CERA”).

To obtain pedigreed populations of seeds from each of these populations, six seeds from

169 each maternal plant were surface sterilized using an $8.9 \%$ bleach solution followed by a $70 \%$

170 ethanol rinse. We used 100 grit sandpaper to scarify the seeds, imbibed them in sterile water for

171 three days, and then planted them in small peat pots. A total of 167 Grey Cloud, 196 McCarthy

172 Lake, and 84 CERA individuals were used to generate pedigreed plants. One seedling per

173 individual was used to represent each distinct field-collected family and was transplanted into a

174 large tree pot with 1 teaspoon of Osmocote $®$ slow release fertilizer (14:14:14) after producing

175 five true leaves. Plants were grown in the University of Minnesota Plant Growth Facilities

176 greenhouse under 16:8-h photoperiod. Hand crosses were made according to a nested paternal

177 half-sibling design (North Carolina Design I; Comstock and Robinson 1948), with independent

178 sets of three dams randomly assigned to sires. Hand crosses were performed daily, and all non-

179 pollinated flowers were removed. After accounting for mortality in the greenhouse and planting 
180 logistics, the final pedigree consisted of 42 paternal half-sibling families and 124 maternal full-

181 sibling families at Grey Cloud, 48 paternal half-sibling families and 132 maternal full-sibling

182 families at McCarthy Lake, and 21 paternal half-sibling families and 60 maternal full-sibling

183 families at CERA.

Field planting design

In October-November of each of three consecutive years (2014-2016), pedigreed seeds

186 from each respective population were planted into restored tallgrass prairie near to $(<1 \mathrm{~km})$ each

187 site of origin. To maintain the environment for the experimental populations as realistic as

188 possible, vegetation was left in place and only mown (or burned in the case of CERA in 2016

189 and McCarthy Lake in 2014) in the fall to facilitate planting. In Fall of 2014, all rows needed for

190 all three years of the study were laid in parallel two meters apart, each row $50 \mathrm{~m}$ long. For each

191 Fall planting, a subset of rows within blocks was chosen at random, and planting positions were

192 marked with nails at 2 m intervals. Pedigreed seeds were planted at randomly chosen positions

193 according to the following protocol. Seeds from each full-sibling family from the greenhouse

194 crosses were combined and haphazardly distributed into envelopes, such that each envelope

195 contained five seeds. We randomly assigned envelopes to positions along rows in a randomized

196 block design (eight blocks at Grey Cloud and McCarthy Lake, and four blocks at CERA

197 positioned in the same location in all years), resulting in 15-24 replications of each half-sib

198 family per block. Blocks contained 25-26 rows (13 rows at McCarthy Lake). At each position

199 centered at the nail, five seeds from a randomly chosen full-sib family were planted at $10 \mathrm{~cm}$

200 spacing, approximately $1 \mathrm{~cm}$ under the soil surface. 
Fitness surveys

We regularly recorded fitness components for each planted seed throughout the growing season of the following year, including emergence, survival to flowering, and reproductive

204 output (Table 1). A plant was considered present if cotyledons had emerged, and survival to

205 flowering was scored based on the presence of open flowers or evidence of flowering (e.g.,

206 wilted flowers, pedicels, or fruit). At each late-season census (i.e. after flowering), we recorded

207 the number of ripe fruit collected, number of fully elongated but immature fruits collected,

208 number of fruits collected off the ground in the immediate vicinity, number of immature fruits,

209 and pedicels from dehisced fruits remaining on the plant (see Sheth et al. 2018). Herbivory,

210 ranging from light browsing to consumption of the entire plant, or severing of the stem near the

211 soil surface, was recorded throughout the growing season. When herbivory occurred early in the

212 growing season (i.e. June-July), plants sometimes recovered and eventually reproduced.

213 Therefore, we retained these plants in censuses after herbivory to account for this late season

214 seed production. Because individuals ranged widely in number of fruits set (1-68), and fruits

215 explosively dehisce at maturity, we were unable to collect all mature fruits or count all seeds

216 each plant produced. Therefore, seed counts were obtained on a subsample of fruits produced.

217 Subsampling was accounted for in the statistical analyses (see below).

218 Statistical Analyses

219 Estimates of $\overline{\mathrm{W}}$ and $\mathrm{V}_{\mathrm{A}}(\mathrm{W})$ for each population in each year (Geyer et al. 2007; Shaw et

220 al. 2008) we conducted aster analyses, as implemented in the package "aster" (Geyer 2018),

221 using the R 3.5.1 environment (R Core Team 2018). The graphical model for lifetime fitness

222 (Fig. 1) included seedling emergence and survival of plants to flowering, both of which were 
223 modeled as Bernoulli variables, and the number of fruits and seeds produced, which were

224 modeled with Poisson distributions. To account for subsampling of fruits, we followed Appendix

225 S1 of Stanton-Geddes et al. (2012a), incorporating in our graphical models an additional node

226 representing the total number of fruits sampled. This leads to estimates that are scaled up to the

227 total number of seeds produced per seed planted. Using this model for expression of components

228 of fitness through the lifespan, as well as the dependence of each on components expressed

229 earlier, we obtained unconditional estimates, i.e. the mean and additive genetic variance of the

230 number of seeds produced per seed planted.

231 For each population in each year, we conducted separate aster analyses to estimate

$232 \mathrm{~V}_{\mathrm{A}}(\mathrm{W})$, including as predictors parental (genetic) effects and block. As in Sheth et al. (2018),

233 only parental (genetic) effects were treated as random as the basis for estimating $\mathrm{V}_{\mathrm{A}}(\mathrm{W})$. Models

234 including factors whose levels are considered random (i.e. for which the parameter of interest is

235 variance of the levels' effects) were introduced by Fisher (1918) with the motivation of

236 estimating genetic variance of a quantitative trait. The original statistical methodology relies

237 heavily on the convenient mathematical properties of the assumed Gaussian distribution of the

238 random effects. Geyer et al. (2013) outline the theoretical and computational problems that

239 attend relaxation of the Gaussian assumption for the random effects, especially with multiple

240 random factors, in aster models and other GLMM, which are explicitly motivated by the need to

241 model cases that do not meet that assumption (see also Bolker et al. 2009). We follow the

242 recommendation of Geyer (2015, slide 3) to designate as random only those factors necessary to

243 address the questions of scientific interest, here, the parental effects, enabling estimation of

244 genetic variance for fitness. In addition, to test whether parental genetic effects differed among

245 years, we jointly analyzed the data for cohorts grown in all three years, including year as a fixed 
246 factor and parental (genetic) effects and the interaction between parental effects and year

247 (genotype-by-year) as random factors. We tested fixed factors with likelihood ratio tests of the

248 full model vs. models excluding individual factors. To obtain estimates of additive genetic

249 variance for lifetime fitness, we first conducted separate analyses with sire and dam as random

250 factors, finding both significant and roughly comparable in magnitude. We then constructed

251 models that explicitly equated the variance due to sires with that for dams (i.e. modeling the

252 equal nuclear transmission of each parent to their offspring) and estimated a single variance

253 component for their effects (hereafter parental effects), with sire effects being (see Sheth et al.

254 2018). From separate analyses, also including blocks as fixed effects, we estimated $\bar{W}$.

For each population-year combination, mean fitness was represented by the estimate for

256 mean fitness (with its standard error) that is the median value among the estimates of mean

257 fitness for all the blocks of a given site. To visualize breeding values for fitness on the

258 measurement scale (i.e. number of seeds produced per seed planted), we performed non-linear

259 transformations of breeding values on the canonical parameter scale to the mean-value parameter

260 scale using a mapping function that adds a component of a fixed effect (see Table 3 for relevant

261 blocks) to each random parental effect (Geyer and Shaw 2013; de Villemereuil et al. 2016). The

262 resulting values represent estimates of breeding values on the mean-value parameter (i.e.

263 measurement scale). Estimates of $\mathrm{V}_{\mathrm{A}}(\mathrm{W})$ on the measurement scale were obtained via the delta

264 method following Geyer (2019). We obtained asymmetrical 95\% confidence intervals using the

265 parametric bootstrap to obtain a bootstrap-t distribution from the difference between original

266 and 100 bootstrapped $\mathrm{V}_{\mathrm{A}}(\mathrm{W})$ values divided by their standard error (DiCiccio and Efron 1996).

267 Predicted changes in mean fitness from FTNS $\left(\frac{V_{A}(W)}{\bar{W}}\right)$ were added to the estimates of mean

268 fitness $(\overline{\mathrm{W}})$ to generate the predicted mean fitness of the progeny generation. Standard errors 
269 were calculated for predicted changes in fitness $\left(\frac{\mathrm{V}_{A}(\mathrm{~W})}{\overline{\mathrm{W}}}\right)$ following Geyer (2019). Apart from the

270 possibility of seed dormancy, our fitness records cover the entire life history of individual plants,

271 and therefore represent estimates of total absolute fitness over individual life spans.

272 To compare the genetic effects on fitness (breeding values) between years, and the

273 potential for temporal fitness trade-offs, we obtained breeding values for each sire in each year

274 and plotted each sire's value in one year against its breeding value in another for all three

275 combinations of years. We also calculated Pearson's product-moment correlation coefficients

276 between inferred breeding values expressed in different years. We emphasize that these

277 correlations do not account for the uncertainty associated with inferred breeding values; we

278 present them only as a coarse description of association between breeding values expressed in

279 different years. All data and scripts for the results reported here are available at

280 https://github.com/mason-kulbaba/adaptive-capacity.git

281

282 Results

283 Expression of additive genetic variance for lifetime fitness

284 We found highly significant additive genetic variance for lifetime fitness, $\mathrm{V}_{\mathrm{A}}(\mathrm{W})$, in all

285 three years for all three populations, as reflected by significant parental effects in all models

286 (Table 2); block effects were also significant in all cases, indicating spatial variation within sites

287 in expression of fitness. Estimates of $\mathrm{V}_{\mathrm{A}}(\mathrm{W})$ varied widely among years and populations, with

288 the smallest and largest estimates of $\mathrm{V}_{\mathrm{A}}(\mathrm{W})$ found in consecutive years for the Grey Cloud

289 population $\left(\mathrm{V}_{\mathrm{A}}(\mathrm{W})=0.631\right.$ in 2016 , and 6.491 in 2017$)$. The statistical detection of $\mathrm{V}_{\mathrm{A}}(\mathrm{W})$ 
290 (Table 3) implies capacity for genetic response to natural selection based on standing $\mathrm{V}_{\mathrm{A}}(\mathrm{W})$.

291 Probability distributions of breeding values for each of the nine cases are displayed in Fig. 2.

292 Significant genotype-by-year interactions for each population (Table 2) indicated that the

293 expression of parental genetic effects varied among years. Year-specific breeding values within

294 each population revealed large differences between years in family-specific expressions of total

295 lifetime fitness (Fig. 3). Breeding values exhibited small to moderate correlations between years,

296 with two cases of modest negative correlations: 2015 vs. 2016 in McCarthy Lake and 2016 vs.

2972017 in CERA (Fig. 3). The findings of significant genotype-by-year interactions indicate that

298 families contributing disproportionately to the next generation often differ among years.

299

\section{Mean fitness and predicted changes in mean fitness}

The inclusion of block effects in all fixed-effects aster models for $\overline{\mathrm{W}}$ explained significantly more variation than models without (Grey Cloud and McCarthy Lake: all test $\mathrm{df}=7$, all test deviance $>4.26$, all $\mathrm{P}<0.05 ;$ CERA: all test $\mathrm{df}=3$, all test deviance $>27.92$, all $\mathrm{P}<0.0001)$. As with estimates of $\mathrm{V}_{\mathrm{A}}(\mathrm{W})$, estimates of mean fitness varied among populations and years (Table 3; Fig. 4). Mean fitness was highest in the McCarthy Lake site in 2015 (mean and standard error: $3.528 \pm 1.227)$ and lowest in Grey Cloud in $2016(0.640 \pm 0.129)$. This and one other instance (CERA mean and standard error: $0.725 \pm 0.112$ ) indicating declining populations (i.e. $\bar{W}<1$ ) were found in the same year.

The estimates predicting change in mean fitness from Fisher's Fundamental Theorem $\left(\frac{\mathrm{V}_{\mathrm{A}}(\mathrm{W})}{\overline{\mathrm{W}}}\right)$, are biologically meaningful, ranging from increases of just under 1 seed per individual seed planted to about 6 , varying with the magnitude of both $\bar{W}$ and $V_{A}(W)$. The largest increase in mean fitness was predicted for the progeny of Grey Cloud plants after 2017 (mean increase of 
3126.122 seeds per plant) and the smallest for progeny of McCarthy Lake plants after 2016 (mean

313 increase of 0.834 seeds per plant). Notably, we identified two predictions of evolutionary rescue

314 for the progeny generations of 2016 in Grey Cloud and CERA. This predicted increase in mean

315 fitness is consistent with population sustainability and growth of the progeny generations (Table

316 3; Fig. 4).

\section{Discussion}

The immediate capacity for population-level adaptation is strongly dependent on the

319 presence and magnitude of additive genetic variance for lifetime fitness (Fisher 1930; Ewens

320 2004). Our study detected significant and substantial capacity for immediate adaptation through

321 current natural selection on standing levels of $\mathrm{V}_{\mathrm{A}}(\mathrm{W})$ in three populations in three years. Among

322 these nine cases, we detected two instances of populations declining numerically, and in those

323 cases obtained predictions of evolutionary rescue increasing mean fitness to levels consistent

324 with maintaining or increasing population size. Genotype-by-year interactions indicated that

325 genetic effects on fitness differed among years. These interactions reflect differences among

326 years both in the magnitude of $\mathrm{V}_{\mathrm{A}}(\mathrm{W})$ and in genotypic fitness rankings. Predicted change in

327 mean fitness also varied among years, suggesting that the capacity for adaptation is strongly

328 influenced by temporal environmental variation. Below, we discuss the importance of these

329 findings and consider how our results from direct study of the adaptive process in the wild

330 illuminate the potential for ongoing adaptation. We also relate our findings to the potential for

331 evolutionary rescue of declining populations. Finally, we describe how our experimental and

332 analytical approaches overcome obstacles commonly associated with evaluating adaptive

333 capacity in the wild, and we advocate for the broader implementation of these approaches. 


\section{Expression of additive genetic variance for lifetime fitness}

Our detection of prevalent and non-negligible additive genetic variance for lifetime

results contrast with those of several studies that conclude limited capacity for adaptation,

341 through estimates of heritability of fecundity (e.g. Kruuk et al. 2000), or other individual fitness

342 components (Mousseau and Roff 1987; Matos et al. 2000; McCleery et al. 2004; Teplitsky et al.

343 2009). We suggest that these studies can be reconciled with our findings in part by recognizing

344 that even when additive genetic variances of individual fitness components are modest, estimates

345 of $\mathrm{V}_{\mathrm{A}}(\mathrm{W})$ may be considerably larger due to the compounding of fitness components through an

346 individual's life-history (Shaw et al. 2008; Shaw and Geyer 2010). This compounding plays out

347 over the entire life-history, regardless of the extent to which there are genetically based trade-

348 offs between individual components of fitness (e.g. Rose and Charlesworth 1981). Our analysis

349 of total lifetime fitness through aster modeling enabled us to account for the dependent nature of

350 sequential fitness components in our estimates of total fitness. $\mathrm{V}_{\mathrm{A}}(\mathrm{W})$ may also be obscured by

351 environmental variation (Price and Schluter 1991).

Our finding of prevalent interactions between genotype and year can be partitioned into

353 two aspects of environmental dependence of genetic expression (Falconer 1952). First,

354 correlations between years of family-specific breeding values for lifetime fitness were generally

355 low and, in two cases, slightly negative (Fig. 3). Thus, genotypic contributions of offspring in

356 one year are not predictive of contributions in another year. Interestingly, the two strongest 
genetic correlations between years were not for consecutive years. These modest between-year

358

359

360

361

362

363

364

365

366

367

368

369

370

371

372

373

374

375

376

377

378

379

genetic correlations suggest that the response to selection may not be accompanied by directional

change in the frequency of the same alleles over multiple years. Second, for each population, estimates of $\mathrm{V}_{\mathrm{A}}(\mathrm{W})$ differed strikingly among years (Table 3$)$, though we acknowledge

substantial uncertainty in the estimates. Nevertheless, these differences in estimated $V_{A}(W)$

suggest that the immediate capacity for ongoing adaptation varies among years. Almost

certainly, many aspects of environment, whether slight or major, differed among the years at

each site; to determine which of these influenced genetic disparities in fitness would require

experimental manipulation of particular aspects of the environment, as conducted by Torres-

Martinez et al. (2019).

Whereas we found considerable $\mathrm{V}_{\mathrm{A}}(\mathrm{W})$ for multiple populations, explanations for the maintenance of such potential variation has long been elusive (e.g. Burt 1995). One potential explanation is that trade-offs between individual fitness components maintain additive genetic variation (Barton and Keightley 2002). Our previous work focusing on the Grey Cloud population revealed positive correlations of breeding values between fitness components and also two environments (Sheth et al. 2018). This result suggests that trade-offs (i.e. negative genetic correlations) do not account for the maintenance of observed levels of $V_{A}(W)$.

Temporal environmental variation has long been conjectured to maintain genetic variation, but the theoretical conditions that predict this outcome are restrictive (Felsenstein 1976). Experiments manipulating environmental variation have led to conflicting conclusions on the role of environmental variation in the maintenance of genetic variation (Mackay 1980; Yeaman et al. 2010; Huang et al. 2015). Through estimates of total lifetime fitness, instead of individual traits or components of fitness, our results have documented extensive temporal 
380 variation in the expression of breeding values within populations (Fig. 2; Fig. 3). Given the short

381 timeframe of our study (i.e. single generation replicated over three years), the impact of novel

382 mutations on lifetime fitness would be negligible. Additional phenomena may also contribute to

383 the conservation of genetic variation (e.g., marginal overdominance; Levene 1953; Gillespie

384 1984), but the differential and variable genetic contribution of families to the following progeny

385 generation across years (Fig. 3) is consistent with a role for temporal environmental variation in

386 impeding depletion of $\mathrm{V}_{\mathrm{A}}(\mathrm{W})$ by natural selection. These annual variations may contribute to the

387 maintenance of the appreciable levels of observed $V_{A}(W)$ in our study.

388 Our measures of immediate capacity for adaptation can alternatively be expressed as

389 evolvability (sensu Houle 1992, see Table 3) to yield the change in absolute mean fitness as a

390 proportion of the current absolute mean fitness. This measure of predicted proportional change

391 has been advocated particularly in the context of trait evolution. In the context of predicting

392 change in mean fitness, we view the original formulation of the FTNS as more informative

393 because it is directly interpretable demographically as the predicted change in the per capita

394 contribution of offspring to the population. In contrast, there is no direct demographic

395 interpretation of the corresponding evolvabilities.

Mean fitness and predicted changes in mean fitness

Similar to estimates of $\mathrm{V}_{\mathrm{A}}(\mathrm{W})$, mean fitness and the predicted rate of adaptation across

398 generations varied with population and year. Predictions based on Fisher's Fundamental

399 Theorem $\left(\frac{\mathrm{V}_{\mathrm{A}}(\mathrm{W})}{\overline{\mathrm{W}}}\right)$ indicated that even the more modest estimates of $\mathrm{V}_{\mathrm{A}}(\mathrm{W})$ (e.g., Grey Cloud and

400 CERA in 2016; Table 3) were sufficient to increase mean fitness under contemporary natural

401 selection. In the case of the largest estimate of $\mathrm{V}_{\mathrm{A}}(\mathrm{W})$ (Grey Cloud in 2017), contemporary 
402

403

404

405

406

407

408

409

410

411

412

413

414

415

416

417

418

419 wild.

420 Our assessments of fitness encompass components of fitness expressed across the entire life span

421 of individuals, from each seed planted through to the seeds it produced; these fitness evaluations

422 are thus uncommonly complete. Nevertheless, some aspects of fitness are not included. For

423 example, this study did not account for fitness realized through siring of seeds (male fecundity).

424 In a companion study, however, Kulbaba and Shaw (in review) found positive genetic 
correlations between lifetime fitness measured as maternal contributions (seeds set) and lifetime

426 fitness measured through paternal contributions (seeds sired), regardless of population density

427 and genetic relatedness among individuals. We therefore expect paternal-specific fitness to scale

428 proportionately with maternal-specific fitness. A second omission from our fitness estimates is

429 the potential for a delayed contribution to fitness due to seed dormancy. Partial surveys of

430 germination in later years found low emergence from seeds planted earlier than the previous Fall,

431 representing a modest proportion of each cohort. Moreover, in increasing populations, (i.e.

$432 \overline{\mathrm{W}}>1$ ), as we found in most cases, delays in an individual's life-cycle are expected to have a

433 discounting effect on its contributions to fitness (Roughgarden 1996, Eqs. 18.31, p. 331). On the

434 temporal scale of adaptation of annual populations between consecutive years, which is our

435 present focus, it is valid to neglect such delays. To address ongoing adaptation on longer time

436 scales, further studies that include instances of delayed germination in estimates of fitness, with

437 appropriate discounting, as in Eck et al. (2015) would be worthwhile. This is especially so, in

438 view of our finding of weak correspondence of genetic selection between consecutive years (Fig.

$4393)$.

$440 \quad$ Our study has generated precise quantitative predictions of genetic change in mean

441 fitness. However, correspondence between predicted genetic change in mean fitness across

442 generations and the change in mean fitness that is realized remains to be assessed. We are

443 currently evaluating this correspondence to address the accuracy of predictions of the rate of

444 adaptation from Fisher's FTNS for these populations.

445 Conclusions

Whereas numerous authors invoke relentless selection to explain limited heritability of

447 total fitness, or traits closely related to fitness (Kruuk et al. 2000; Coltman et al. 2005; 
448 McFarlane et al. 2014; de Villemereuil et al. 2019), our results demonstrate the persistence of

449 high $\mathrm{V}_{\mathrm{A}}(\mathrm{W})$ despite contemporary selection. Significant interactions between genotype and year

450 reflected modest correlations between years of family-specific breeding values for lifetime

451 fitness, as well as estimates of $\mathrm{V}_{\mathrm{A}}(\mathrm{W})$ that varied widely across years. Along with estimates of

$452 \mathrm{~V}_{\mathrm{A}}(\mathrm{W})$, mean absolute fitness varied among sites and years. Using Fisher's Fundamental

453 Theorem, we predicted the rate of adaptation, and two instances of evolutionary rescue from

454 standing $\mathrm{V}_{\mathrm{A}}(\mathrm{W})$ under contemporary natural selection. Our results reveal the power and utility of

455 Fisher's Fundamental Theorem to identify the capacity for adaptation, and to generate

456 quantitative predictions for fitness increase in the wild.

457 Our experimental approach in combination with aster analyses for total lifetime fitness

458 provided a direct estimate of $\mathrm{V}_{\mathrm{A}}(\mathrm{W})$ and fitness change (Shaw 2019). Many studies concerning

459 the potential for adaptation rely on indirect estimates of fitness, and often focus on one or a few

460 individual traits or fitness components, thus omitting the role of multiple life-history fitness

461 expressions. Our approach to evaluating total lifetime fitness with aster models provides a more

462 complete picture of fitness and $\mathrm{V}_{\mathrm{A}}(\mathrm{W})$. We recommend our empirical and analytical strategy for

463 future studies of other organisms having different life-histories to more fully characterize the

464 capacity for ongoing adaptation. 
468 Antonovics, J., and A. D. Bradshaw. 1970. Evolution in closely adjacent plant populations VIII.

$469 \quad$ Clinal patterns at a mine boundary. Heredity 25:349-362.

470 Barrett, R., and D. Schluter. 2008. Adaptation from standing genetic variation. Trends in Ecology \& Evolution 23:38-44.

472 Barton, N. H., and P. D. Keightley. 2002. Understanding quantitative genetic variation. Nature Reviews Genetics 3:11-21.

474 Baucom, R. S. 2019. Evolutionary and ecological insights from herbicide resistant weeds: what have we learned about plant adaptation, and what is left to uncover? New Phytologist, doi: 10.1111/nph.15723.

477 Bell, G. 2017. Evolutionary rescue. Annual Review of Ecology, Evolution, and Systematics 48:605-627.

479 Bell, G., and A. Gonzalez. 2011. Adaptation and evolutionary rescue in metapopulations experiencing environmental deterioration. Science 332:1327-1330.

481 Bell, G., and A. Gonzalez. 2009. Evolutionary rescue can prevent extinction following environmental change. Ecology Letters 12:942-948.

483 Bolker, B. M., M. E. Brooks, C. J. Clark, S. W. Geange, J. R. Poulsen, M. H. H. Stevens, and J.evolution. Trends in Ecology \& Evolution 24:127-135. 
Bradshaw, A. D. 1991. The Croonian Lecture, 1991. Genostasis and the limits to evolution. 333:289-305.

Burt, A. 1995. The evolution of fitness. Evolution 49:1-8.

490 Carlson, S. M., C. J. Cunningham, and P. A. H. Westley. 2014. Evolutionary rescue in a changing world. Trends in Ecology \& Evolution 29:521-530.

Coltman, D. W., P. O’Donoghue, J. T. Hogg, and M. Festa-Bianchet. 2005. Selection and genetic (co)variance in bighorn sheep. Evolution 59:1372-1382.

494 Comstock, R. E., and H. F. Robinson. 1948. The components of genetic variance in populations of biparental progenies and their use in estimating the average degree of dominance.

497 Conner, J. 1988. Field measurements of natural and sexual selection in the fungus beetle, Bolitotherus cornutus. Evolution 42:736-749.

499 Conner, J. K., S. Rush, and P. Jennetten. 1996a. Measurements of natural selection on floral traits in wild radish (Raphanus raphanistrum ). I. Selection through lifetime female

Conner, J. K., S. Rush, S. Kercher, and P. Jennetten. 1996b. Measurements of natural selection on floral traits in wild radish (Raphanus raphanistrum ). II. Selection through lifetime male and total fitness. Evolution 50:1137-1146. 
de Villemereuil, P., H. Schielzeth, S. Nakagawa, and M. Morrissey. 2016. General methods for evolutionary quantitative genetic inference from generalized mixed models. Genetics 204:1281-1294. Genetics.

DiCiccio, T. J., and B. Efron. 1996. Bootstrap confidence intervals. Statistical Science 11:189_228.

Eck, D. J., R. G. Shaw, C. J. Geyer, and J. G. Kingsolver. 2015. An integrated analysis of phenotypic selection on insect body size and development time. Evolution 69:2525-2532.

Etterson, J. R. 2004a. Evolutionary potential of Chamaecrista fasciculata in relation to climate change. I. Clinal patterns of selection along an environmental gradient in the great plains.

Etterson, J. R. 2004b. Evolutionary potential of Chamaecrista fasciculata in relation to climate change. II. Genetic architecture of three populations reciprocally planted along an

Etterson, J. R., and R. G. Shaw. 2001. Constraint to adaptive evolution in response to global

523 Ewens, W. J. 2004. Mathematical Population Genetics. 2nd ed. Springer.

524 Felsenstein, J. 1976. The theoretical population genetics of variable selection and migration. Annual Review of Genetics 10:253-280. 293-298.

528 Fenster, C. B. 1991a. Gene flow in Chamaecrista fasciculata (Leguminosae) I. Gene dispersal. Evolution 45:398-409. 
Fenster, C. B. 1991b. Gene flow in Chamaecrista fasciculata (Leguminosae) II. Gene establishment. Evolution 45:410-422.

532 Fisher, R. A. 1930. The Genetical Theory of Natural Selection. Oxford: Claredon Press.

533 Fisk, D. L., L. C. L. Iv, R. A. Knapp, and M. E. Pfrender. 2007. Rapid evolution in response to introduced predators I: rates and patterns of morphological and life-history trait divergence. BMC Evolutionary Biology 22.

Foerster, K., T. Coulson, B. C. Sheldon, J. M. Pemberton, T. H. Clutton-Brock, and L. E. B. Kruuk. 2007. Sexually antagonistic genetic variation for fitness in red deer. Nature

Franks, S. J., S. Sim, and A. E. Weis. 2007. Rapid evolution of flowering time by an annual plant in response to a climate fluctuation. Proceedings of the National Academy of Science adaptation. Evolution 54:1173-1181.

544 Geerts, A. N., J. Vanoverbeke, B. Vanschoenwinkel, W. Van Doorslaer, H. Feuchtmayr, D. 104:1278-1282.

Geyer, C. J. 2018. aster: Aster Models. R package version 0.9.1.1. https://cran.rAtkinson, B. Moss, T. A. Davidson, C. D. Sayer, and L. De Meester. 2015. Rapid project.org/package $=$ aster. and genetic effects on fitness: Calculations for exponential family models with random effects. The Annals of Applied Statistics 7:1778-1795. 
553 Geyer, C. J., and R. G. Shaw. 2013. Aster models with random effects and additive genetic

$554 \quad$ variance for fitness. Accessed June 24, 2018. https://conservancy.umn.edu/handle/11299/152355.

556 Geyer, C. J., S. Wagenius, and R. G. Shaw. 2007. Aster models for life history analysis. Biometrika 94:415-426.

558 Gillespie, J. H. 1984. Pleiotropic overdominance and the maintenance of genetic variation in polygenic characters. Genetics 107:321-330.

560 Gomulkiewicz, R., and R. D. Holt. 1995. When does evolution by natural selection prevent extinction? Evolution 49:201-207.

562 Hartl, D. L., and A. G. Clark. 1997. Principles of population Genetics. 3rd ed. Sinauer.

563 Houle, D. 1992. Comparing evolvability and variability of quantitative traits. Genetics 130:195204.

565 Huang, Y., J. R. Stinchcombe, and A. F. Agrawal. 2015. Quantitative genetic variance in experimental fly populations evolving with or without environmental heterogeneity: quantitative genetic variance. Evolution 69:2735-2746.

568 Irwin, H., and R. Barneby. 1982. The American Cassiinaea synoptical revision of Leguminosae tribe Cassieae subtribe Cassiinae in the New World. Memoirs of the New York Botanical Garden 35:1-918.

571 Janzen, F. J. 1993. An experimental analysis of natural selection on body size of hatchling turtles. Ecology 74:332-341.

573 Kelly, C. A. 1993. Quantitative genetics of size and phenology of life-history traits in Chamaecrista fasciculata. Evolution 47:88-97. 
575 Kruuk, L. E. B., T. H. Clutton-Brock, J. Slate, J. M. Pemberton, S. Brotherstone, and F. E. National Academy of Sciences 97:698-703.

578 Legume, Cassia fasciculata. Ecology 63:1363-1373.

Levene, H. 1953. Genetic equilibrium when more than one ecological niche is available. The American Naturalist 87:331-333.

Mackay, T. F. C. 1980. Genetic variance, fitness, and homeostasis in varying environments: an experimental check of the theory. Evolution 34:1219-1222.

Matos, Rose, M. T. R. Pite, Rego, and Avelar. 2000. Adaptation to the laboratory environment in Drosophila subobscura. Journal of Evolutionary Biology 13:9-19.

Mazer, S. J. 1987. The Quantitative genetics of lifehistory and fitness components in Raphanus raphanistrum L. (Brassicaceae): ecological and evolutionary consequences of seedweight variation. The American Naturalist 130:891-914.

McCleery, R. H., R. A. Pettifor, P. Armbruster, K. Meyer, B. C. Sheldon, and C. M. Perrins. 2004. Components of variance underlying fitness in a natural population of the great tit Parus major. The American Naturalist 164:E62-E72.

McFarlane, S. E., J. C. Gorrell, D. W. Coltman, M. M. Humphries, S. Boutin, and A. G. McAdam. 2014. Very low levels of direct additive genetic variance in fitness and fitness components in a red squirrel population. Ecology and Evolution 4:1729-1738. 
Messer, P. W., S. P. Ellner, and N. G. Hairston. 2016. Can population genetics adapt to rapid evolution? Trends in Genetics 32:408-418.

Moose, S. P., J. W. Dudley, and T. R. Rocheford. 2004. Maize selection passes the century mark: a unique resource for 21st century genomics. Trends in Plant Science 9:358-364.

Mousseau, T. A., and D. A. Roff. 1987. Natural selection and the heritability of fitness components. Heredity 59:181-197.

Neumann, M., V. Mues, A. Moreno, H. Hasenauer, and R. Seidl. 2017. Climate variability drives recent tree mortality in Europe. Global Change Biology 23:4788-4797.

Pemberton, J. M. 2010. Evolution of quantitative traits in the wild: mind the ecology. Philosophical Transactions of the Royal Society B: Biological Sciences 365:2431-2438.

Price, G. R. 1972. Fisher's fundamental theorem made clear. Annals of Human Genetics 36:129_140.

Price, M. V. 1970. Selection and covariance. Nature 227:520-521.

610 Price, T., and D. Schluter. 1991. On the low heritability of life-history. Evolution 45:853-861.

611 R Core Team. 2018. R: A language and environment for statistical computing. R Foundation for Statistical Computing, Vienna, Austria. https://www.R-project.org/.

613 Roff, D. A., and T. A. Mousseau. 1987. Quantitative genetics and fitness: lessons from Drosophila. Heredity 58:103-118.

615 Rose, M. R., and B. Charlesworth. 1981. Genetics of life history in Drosophila melanogaster. II. Exploratory selection experiments. Genetics 97:187-196.

617 Roughgarden, J. 1996. The theory of population genetics and evolutionary ecology: An introduction. Prentice Hall. 
619 Sæther, B.-E., and S. Engen. 2015. The concept of fitness in fluctuating environments. Trends in Ecology \& Evolution 30:273-281.

621 Shaw, R. G. 2019. From the past to the future: considering the value and limits of evolutionary prediction. The American Naturalist 193:1-10.

Shaw, R. G., and J. R. Etterson. 2012. Rapid climate change and the rate of adaptation: insight from experimental quantitative genetics. New Phytologist 195:752-765.

Shaw, R. G., and C. J. Geyer. 2010. Inferring fitness landscapes: inferring fitness landscapes. Evolution 64:2510-2520.

Shaw, R. G., C. J. Geyer, S. Wagenius, H. H. Hangelbroek, and J. R. Etterson. 2008. Unifying life-history analyses for inference of fitness and population growth. The American naturalist 172:E35-47.

Shaw, R. G., and F. H. Shaw. 2014. Quantitative genetic study of the adaptive process. Heredity

Sheth, S. N., M. W. Kulbaba, R. E. Pain, and R. G. Shaw. 2018. Expression of additive genetic variance for fitness in a population of partridge pea in two field sites. Evolution 72:25372545 .

Stanton-Geddes, J., R. G. Shaw, and P. Tiffin. 2013. Insights from population genetics for range limits of a widely distributed native plant. American Journal of Botany 100:744-753. Geographic Range Location Affect Plant Fitness. PLOS ONE 7:e36015.

Stanton-Geddes, J., P. Tiffin, and R. G. Shaw. 2012b. Role of climate and competitors in limiting fitness across range edges of an annual plant. Ecology 93:1604-1613. 
641 Teplitsky, C., J. A. Mills, J. W. Yarrall, and J. Merilä. 2009. Heritability of fitness components in a wild bird population. Evolution 63:716-726.

643 Thomas, S. C., J. M. Pemberton, and W. G. Hill. 2000. Estimating variance components in 644 natural populations using inferred relationships. Heredity 84:427-436.

645 Torres-Martínez, L., N. McCarten, and N. C. Emery. 2019. The adaptive potential of plant populations in response to extreme climate events. Ecology Letters 22:866-874.

647 Vigueira, C. C., K. M. Olsen, and A. L. Caicedo. 2013. The red queen in the corn: agricultural weeds as models of rapid adaptive evolution. Heredity 110:303-311.

649 Winn, A. A. 2004. Natural selection, evolvability and bias due to environmental covariance in the field in an annual plant: Bias in phenotypic selection gradients. Journal of

652 Yeaman, S., Y. Chen, and M. C. Whitlock. 2010. No effect of environmental heterogeneity on the maintenance of genetic variation in wing shape in Drosophila melanogaster:

Yi, X., and A. M. Dean. 2013. Bounded population sizes, fluctuating selection and the tempo and mode of coexistence. Proceedings of the National Academy of Sciences 110:16945-

658 Zhang, X.-S. 2012. Fisher's geometrical model of fitness landscape and variance in fitness within a changing environment. Evolution 66:2350-2368. 
664 Table 1

665 Table 1. Range of dates for collection of fitness expression data, for three sites of Chamaecrista

666 fasciculata, over three consecutive years.

\begin{tabular}{|l|c|c|c|}
\hline & \multicolumn{3}{|c|}{ Year } \\
\hline \multicolumn{1}{|c|}{ Site } & 2015 & 2016 & 2017 \\
\hline Grey Cloud & June 1 - October 1 & June 10 - October 7 & June 5 - October 3 \\
\hline McCarthy Lake & May 27 - September 25 & June 7 - October 11 & June 8 - October 5 \\
\hline CERA & May 10 - September 23 & June 2 - September 29 & June 1 - October 23 \\
\hline
\end{tabular}


669 Table 2. Summary from aster models testing the fixed effects of block and year, the random

670 factors of combined parental effects, and the interaction between parental effects and year on

671 individual lifetime fitness. Statistical significance of predictor variables was assessed using

672 likelihood ratio tests, and random parental effects were assessed from summary output of aster

673 analyses.

\begin{tabular}{|c|c|c|c|}
\hline Model & Test df & Test deviance & $\mathrm{P}$ \\
\hline \multicolumn{4}{|c|}{ Grey Cloud - Gx Year model } \\
\hline Block & 23 & 159.91 & $\mathrm{P}<0.0001$ \\
\hline Year & 2 & 47.28 & $\mathrm{P}<0.0001$ \\
\hline Parental effects & -- & -- & $\mathrm{P}<0.0001$ \\
\hline Year $x$ Parental effects & -- & -- & $\mathrm{P}<0.0001$ \\
\hline \multicolumn{4}{|c|}{ McCarthy Lake $-G x$ Year model } \\
\hline Block & 23 & 159.91 & $\mathrm{P}<0.001$ \\
\hline Year & 2 & 47.28 & $\mathrm{P}<0.001$ \\
\hline Parental effects & -- & -- & $P<0.0001$ \\
\hline Year $x$ Parental effects & -- & -- & $\mathrm{P}<0.0001$ \\
\hline \multicolumn{4}{|l|}{ CERA $-G \times$ Year model } \\
\hline Block & 11 & 189.80 & $\mathrm{P}<0.0001$ \\
\hline Year & 2 & 58.95 & $\mathrm{P}<0.0001$ \\
\hline Parental effects & - & -- & $\mathrm{P}<0.0001$ \\
\hline Year $x$ Parental effects & - & -- & $\mathrm{P}<0.0001$ \\
\hline
\end{tabular}

674 
676 Table 3. Additive genetic variance for fitness $\left(\mathrm{V}_{\mathrm{A}}(\mathrm{W})\right)$ and $95 \%$ confidence intervals, mean fitness $(\overline{\mathrm{W}}$ and 677 standard error, predicted change in mean fitness $\left(\frac{\mathrm{V}_{\mathrm{A}}(\mathrm{W})}{\overline{\mathrm{W}}}\right)$ and standard error, and predicted mean fitness of 678 second generation determined for each of three sites and three years of Chamaecrista fasciculata. Block used to 679 estimate mean fitness indicated in parentheses after year.

\begin{tabular}{|c|c|c|c|c|c|}
\hline $\begin{array}{l}\text { Site/Year } \\
\text { (Block) }\end{array}$ & $\begin{array}{l}\text { Number of } \\
\text { Seeds } \\
\text { Planted }\end{array}$ & $\begin{array}{c}\mathrm{V}_{\mathrm{A}}(\mathrm{W}) \\
(\mathrm{SE})\end{array}$ & $\begin{array}{c}\overline{\mathrm{W}} \\
(\mathrm{SE})\end{array}$ & $\begin{array}{l}\frac{\mathrm{V}_{\mathrm{A}}(\mathrm{W})}{\overline{\mathrm{W}}} \\
(\mathrm{SE})\end{array}$ & $\begin{array}{c}\text { Predicted Fitness } \\
\text { of Gen. } 2\end{array}$ \\
\hline \multicolumn{6}{|c|}{ Grey Cloud Dunes } \\
\hline 2015 (Block 6) & 3658 & $\begin{array}{c}1.858 \\
(0.558,3.021)\end{array}$ & $\begin{array}{c}1.11 \\
(0.17)\end{array}$ & $\begin{array}{r}1.67 \\
(0.23)\end{array}$ & 2.78 \\
\hline 2016 (Block 6) & 3660 & $\begin{array}{c}0.830 \\
(0.193,1.410)\end{array}$ & $\begin{array}{l}0.64 \\
(0.13)\end{array}$ & $\begin{array}{r}1.30 \\
(0.14)\end{array}$ & 1.94 \\
\hline 2017 (Block 7) & 3660 & $\begin{array}{c}6.491 \\
(1.365,9.161)\end{array}$ & $\begin{array}{l}1.06 \\
(0.34)\end{array}$ & $\begin{array}{l}6.11 \\
(2.32)\end{array}$ & 7.17 \\
\hline \multicolumn{6}{|l|}{ McCarthy Lake } \\
\hline 2015 (Block 4) & 3445 & $\begin{array}{c}3.528 \\
(1.393,16.503)\end{array}$ & $\begin{array}{l}3.02 \\
(1.23)\end{array}$ & $\begin{array}{l}1.17 \\
(0.89)\end{array}$ & 4.19 \\
\hline 2016 (Block 5) & 3480 & $\begin{array}{c}1.572 \\
(0.563,5.103)\end{array}$ & $\begin{array}{l}1.88 \\
(0.57)\end{array}$ & $\begin{array}{l}0.84 \\
(0.18)\end{array}$ & 2.72 \\
\hline 2017 (Block 6) & 3516 & $\begin{array}{c}1.410 \\
(0.610,2.157)\end{array}$ & $\begin{array}{c}1.08 \\
(0.18)\end{array}$ & $\begin{array}{l}1.31 \\
(0.18)\end{array}$ & 2.39 \\
\hline
\end{tabular}


bioRxiv preprint doi: https://doi.org/10.1101/601682; this version posted July 18,2019 . The copyright holder for this preprint (which was not certified by peer review) is the author/funder, who has granted bioRxiv a license to display the preprint in perpetuity. It is made available under aCC-BY 4.0 International license.

\begin{tabular}{|l|c|c|c|c|c|}
\hline \multicolumn{1}{|l|}{ CERA } & 3.204 & 1.80 & 1.79 & 3.58 \\
\hline 2015 (Block 1) & 1845 & $(0.983,6.922)$ & $(0.24)$ & $(0.65)$ & \\
\hline 2016 (Block 2) & 1750 & 0.856 & 0.73 & 1.18 & 1.91 \\
& & $(0.295,2.301)$ & $(0.11)$ & $(0.13)$ & \\
\hline 2017 (Block 3) & 1750 & 1.573 & 1.24 & 1.27 & \\
& & $(0.383,3.694)$ & $(0.25)$ & $(0.49)$ & \\
\hline
\end{tabular}


A

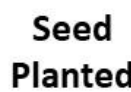

\section{Emergence}

Flowering

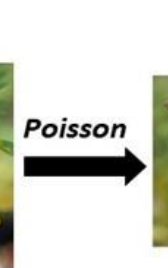

Fruit Production

Seed
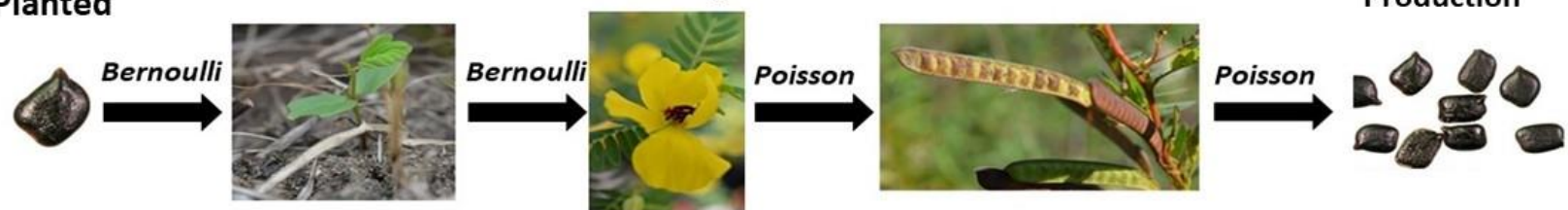

B

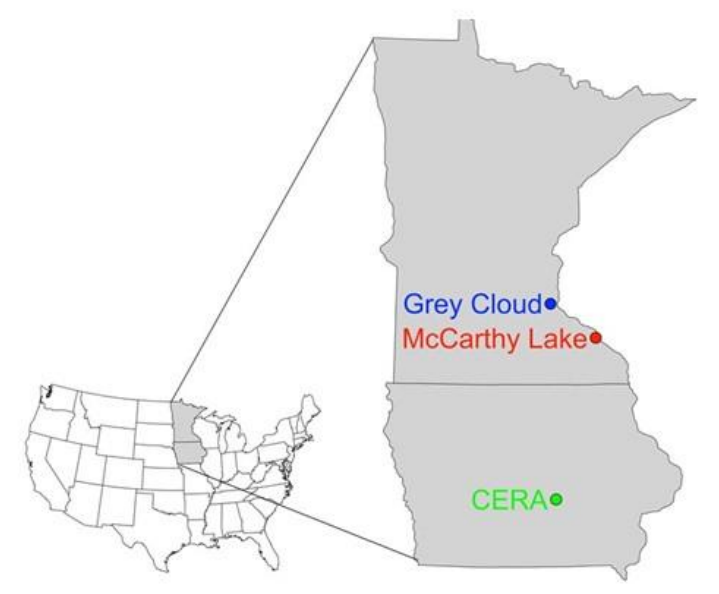

Figure 1 (A) Graphical model used to estimate lifetime fitness. Each node represents a fitness component and

flowering ( 0 or 1 ; Bernoulli distribution), and total number of fruits and seeds produced (Poisson distribution).

Additional node to account for subsampling of total fruit production (not shown) also followed a Poisson

distribution. (B) Map of three experimental populations. Seed photos from Anna Peschel and remaining photos

by MWK. 


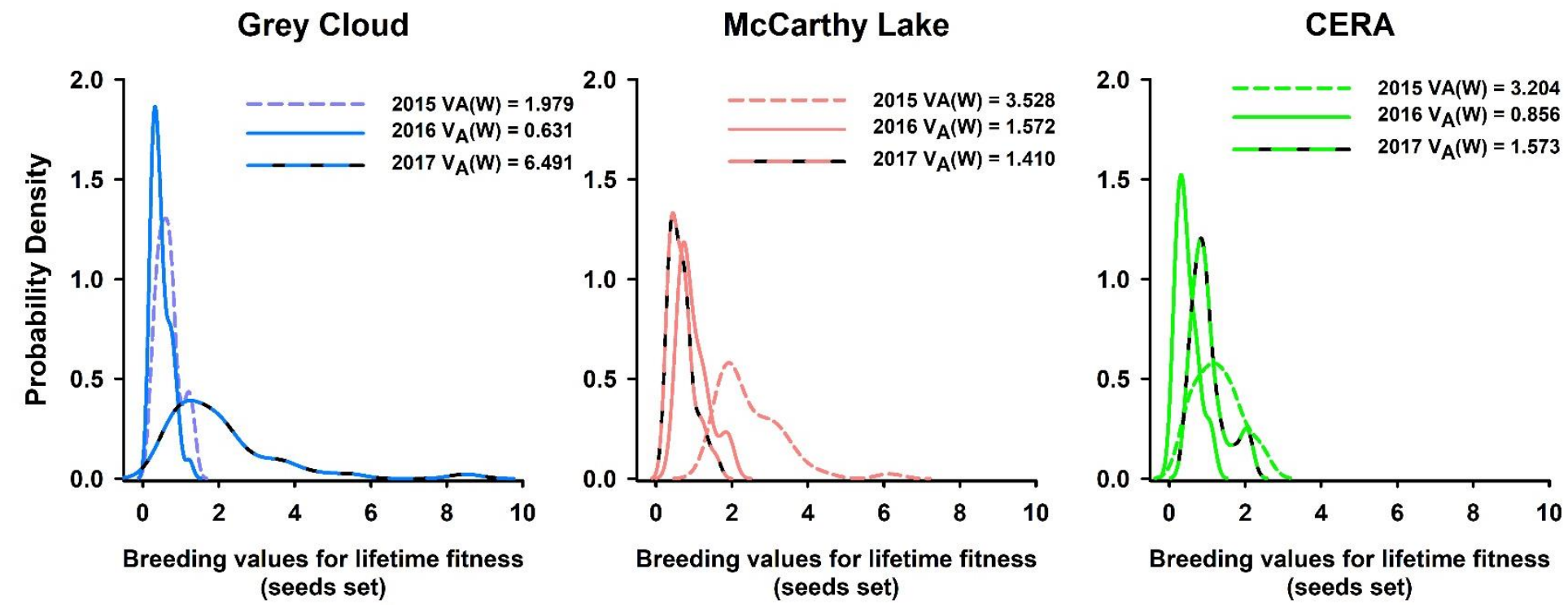

Figure 2. Additive genetic variation for lifetime fitness for three populations of Chamaecrista fasciculata, in

693 three consecutive years. Lines represent probability density distributions of estimated breeding values for

694 lifetime fitness (seeds set). 

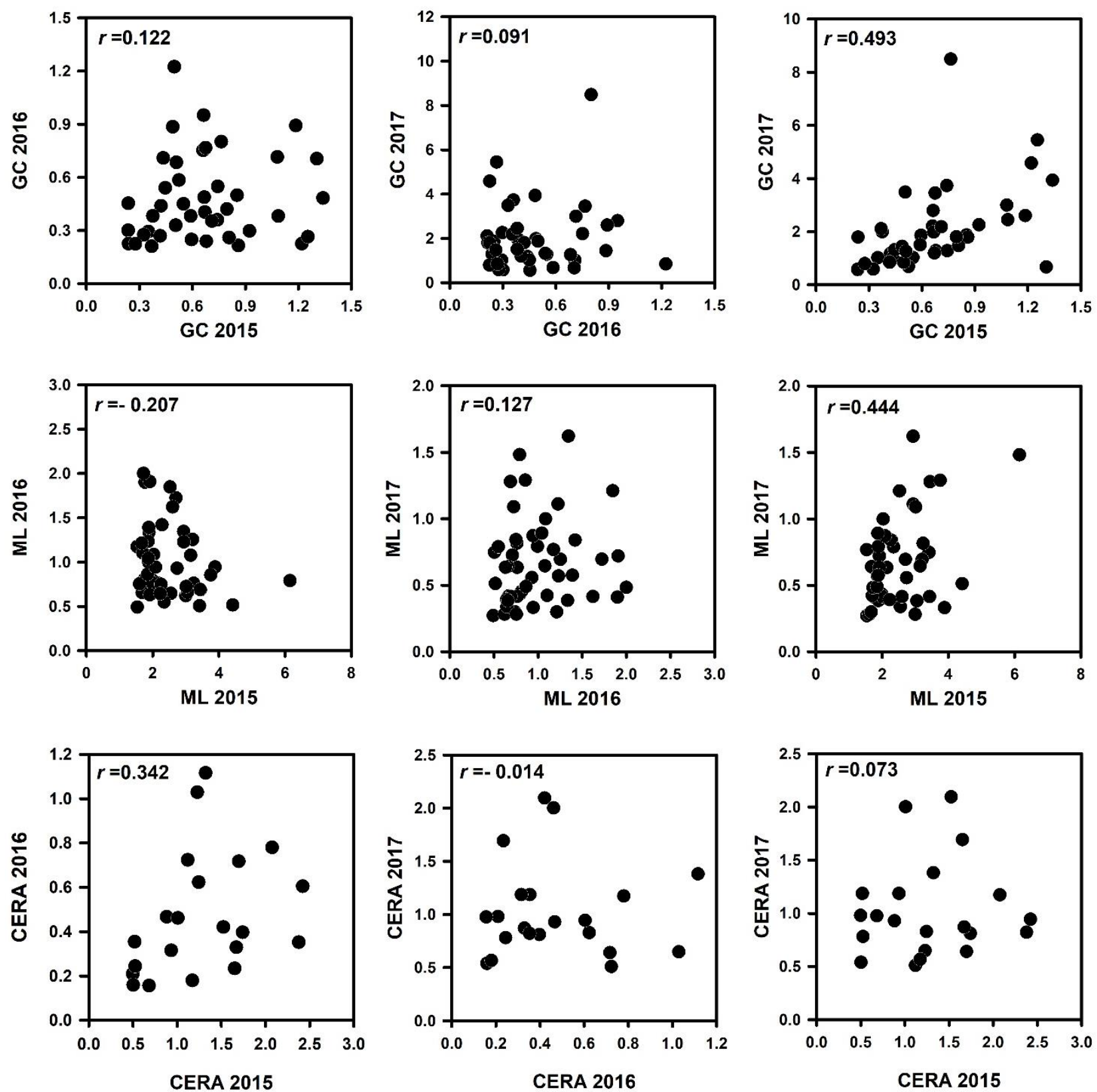

697 Figure 3. Paternal family-specific breeding values for lifetime fitness (seeds set) compared across three

698 consecutive years in three populations of Chamaecrista fasciculata. Pearson correlation coefficients do not account for error associated with estimates of breeding values and are therefore presented as a coarse description of the interannual relationship between breeding values. Please note differences in scale across panels. 
Grey Cloud Dunes

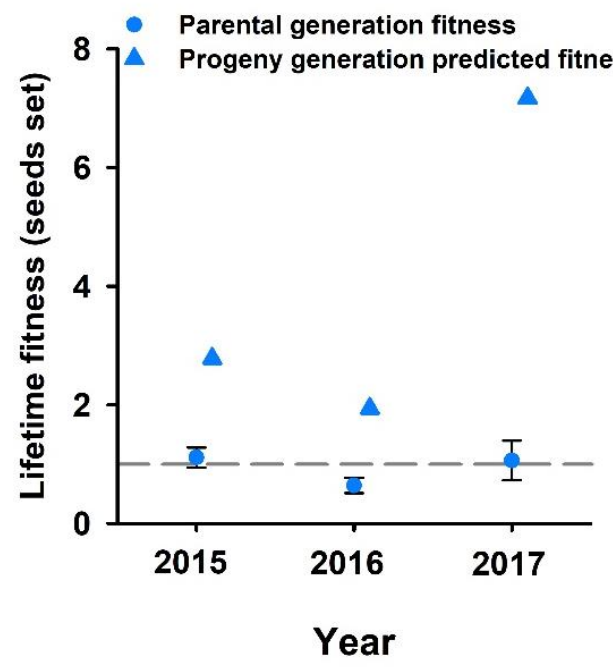

McCarthy Lake

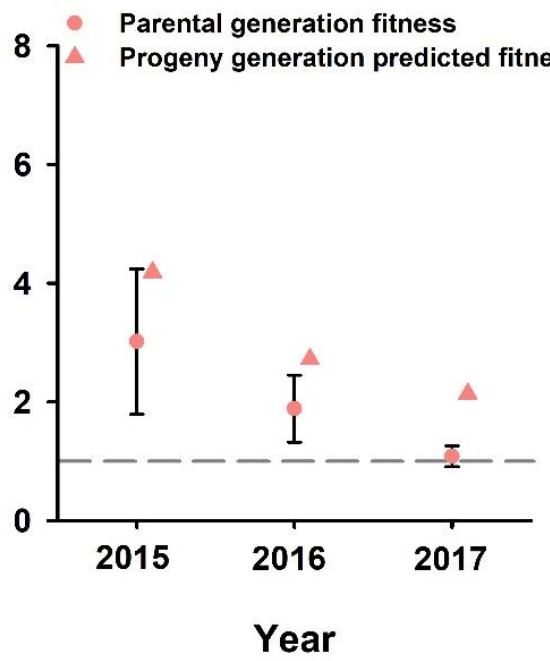

CERA

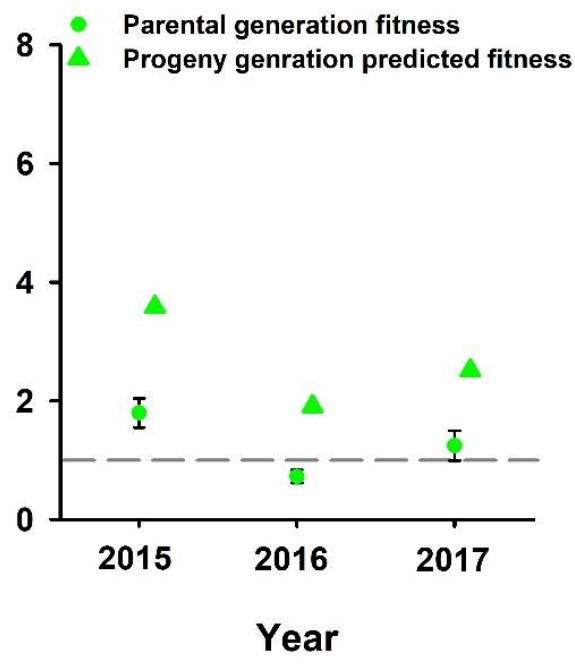

703 Figure 4. Estimated mean fitness of parental (circles with standard errors) and progeny generations (triangles

704 with standard errors) for three populations of Chamaecrista fasciculata in three consecutive years. Horizontal

705 dashed lines represent mean fitness of 1, indicating individual replacement and population stability. 